\title{
Jill Anderson, The meaning beyond the dress: alterity and economy of desire in Mallarmé's "Berthe Morisot"
}

\section{Erica Tacchino}

\section{(2) OpenEdition}

1 Journals

\section{Edizione digitale}

URL: https://journals.openedition.org/studifrancesi/46165

DOI: 10.4000/studifrancesi.46165

ISSN: 2421-5856

\section{Editore}

Rosenberg \& Sellier

\section{Edizione cartacea}

Data di pubblicazione: 1 octobre 2007

Paginazione: 470-471

ISSN: 0039-2944

\section{Notizia bibliografica digitale}

Erica Tacchino, «Jill Anderson, The meaning beyond the dress: alterity and economy of desire in

Mallarmé's "Berthe Morisot"», Studi Francesi [Online], 152 (LI | II) | 2007, online dal 30 novembre 2015, consultato il 24 novembre 2021. URL: http://journals.openedition.org/studifrancesi/46165 ; DOI:

https://doi.org/10.4000/studifrancesi.46165

Questo documento è stato generato automaticamente il 24 novembre 2021.

\section{(c) 9 (i) $\Theta$}

Studi Francesi è distribuita con Licenza Creative Commons Attribuzione - Non commerciale - Non opere derivate 4.0 Internazionale. 


\title{
Jill Anderson, The meaning beyond the dress: alterity and economy of desire in Mallarmé's "Berthe Morisot"
}

\author{
Erica Tacchino
}

\section{NOTIZIA}

JILL ANDERSON, The meaning beyond the dress: alterity and economy of desire in Mallarmé's

"Berthe Morisot", French Studies LX, Number 1, January 2006, pp. 33-48.

1 Il presente articolo è dedicato al tardo testo in prosa di Stéphane Mallarmé, dedicato a Berthe Morisot (1896), che egli introduce come prefazione al catalogo della mostra consacrata alla pittrice impressionista.

2 Jill Anderson persegue scrupolosamente il fine di mostrare come due artisti, di genere e gender differenti come poeta e pittrice, giungano ad accostarsi l'uno all'altro attraverso un reciproco scambio interculturale. Infatti l'A. sostiene che la Morisot sia uno degli autres privilegiati di Mallarmé perché attraverso di lei il poeta riesce a completare il suo sé. La studiosa evidenzia l'immagine di alterità presente nel testo in questione, poiché viene rappresentato un incontro erotizzato con un Altro femmina che concede al narratore di prendere il suo posto appropriandosi delle sue tele e contemplando la nudità della sua modella. Da questo presupposto si comprende come le traiettorie dei due artisti si intersechino: lo scrittore elogia la pittrice dichiarandola "moderna" in quanto intravede in lei il suo stesso senso artistico; dal momento in cui ne osserva i quadri riconosce la sua poesia, ovvero quella poésie à côté de la loi che rifiuta il verso libero per mantenere delle regole, pur senza venir meno al sentiment; così, anche la Morisot tende a delineare un codice nelle sue tele perché sembra avere timore dell'unione tra desiderio e intelletto, e proprio come Mallarmé completa il suo sé con elementi esterni, che ritroviamo nell'esotismo del japonisme, e che permettono alla 
pittrice di proiettare il suo desiderio su un altro Paese o su altri individui sempre rimanendo all'interno di determinati canoni artistici. 